\title{
Estimativa de qualidade de carvão por meio de perfilagem geofísica de gama natural e resistividade
}

\author{
Coal quality estimation using the geophysical logging \\ of natural gamma and resistivity
}

Vládia de Souza

Engenheira de Minas, Dr., LPM / DEMIN / UFRGS

E-mail:vladiasouza@gmail.com

\section{Paulo Salvadoretti}

Professor, Dr., LPM/DEMIN/UFRGS

E-mail: psalvadoretti@ufrgs.br

João Felipe Coimbra Leite Costa

Professor, Dr., LPM/DEMIN/UFRGS

E-mail:jfelipe@ufrgs.br

Filipe Beretta

Engenheiro de Minas, Mestrando LPM / DEMIN / UFRGS

E-mail: fberetta@ymail.com

Jair Carlos Koppe

Professor, Dr. LPM / DEMIN / UFRGS E-mail: jkoppe@ufrgs.br

\section{Gustavo Antônio Bastiani}

Geólogo, Copelmi Mineração E-mail: gustavo.bastiani@terra.com.br

José Adolfo Carvalho Júnior

Engenheiro de Minas Copelmi Mineração

E-mail: adolfo@copelmi.com.br

\section{Alexandre Grigorieff \\ Engenheiro de Minas Copelmi Mineração E-mail: alex@copelmi.com.br}

\section{Resumo}

Esse estudo investiga a capacidade da técnica de perfilagem geofísica para prever a qualidade do carvão. Nesse contexto, alguns parâmetros químicos do carvão foram determinados por meio de análise laboratorial e, posteriormente, eles foram comparados contra registros de perfilagem geofísica (radiação gama natural e resistividade, especificamente). Os resultados mostraram uma forte correlação entre a emissão de radiação gama natural das camadas de carvão e seu teor de cinzas. Isto permitiu estabelecer um modelo linear simples para estimar teores de cinzas, baseando-se nos dados de perfilagem geofísica, com pequeno erro de estimativa ( $\pm 5 \%$ em média). Além disso, os resultados indicaram que não há correlação entre teor de enxofre ou voláteis e os registros geofísicos. Teores de cinza derivados de valores de gama natural podem ser usados, tal como uma informação secundária para avaliar qualidade de carvão durante a etapa de estimativa de recursos, quando são aplicados métodos geoestatísticos. A metodologia é ilustrada por meio de um estudo de caso em depósito de carvão, localizado na região sul do Brasil.

Palavras-chave: Carvão, perfilagem geofísica, gama natural, cinzas.

\section{Abstract}

This study investigates geophysical logging as a tool to predict coal quality. Some of the coal's chemical parameters were determined by laboratory analysis and were compared against values derived from geophysical logging correlation (natural gamma radiation and resistivity versus ash content, specifically). The results showed a strong correlation between the coal's natural gamma emissions and their ash content. From this correlation, a simple linear model was obtained and used to estimate ash grades, directly from geophysical logging records. The error of these predictions is less than $\pm 5 \%$. Additionally, results showed no correlation between the sulphur grade, or volatile matter, and the geophysical records. Ash grades derived from natural gamma ray values can be usedas secondary information to evaluate coal quality during resource estimation, when combined with lab analysis and appropriate geostatiscal methods. The methodology is illustrated by means of a case study at a coal deposit located in southern Brazil.

Keywords: Coal, geophysical logging, natural gamma ray, ashes. 


\section{Introdução \\ Perfilagem geofísica aplicada a mineração de carvão}

A técnica de perfilagem geofísica tem se tornado promissora na mineração de carvão, em especial por sua capacidade de discriminar estratos carbonosos e pela potencialidade na substituição de análises laboratoriais, as quais determinam as propriedades físicas e químicas de interesse necessárias para elaboração dos projetos de lavra e beneficiamento. Análises laboratoriais são, geralmente, efetivadas a partir de amostras obtidas por sondagem rotativa com recuperação de testemunhos, enquanto que a perfilagem geofísica é executada ao longo de furos não necessariamente feitos com essa finalidade. A perfilagem registra variações em propriedades das rochas interceptadas pelos furos e, eventualmente, mostra registros, os quais se correlacionam com os litotipos presentes no depósito. Como a técnica é capaz de identificar o contraste dos propriedades físicas e químicas das rochas, pode ser usada para prever parâmetros qualitativos e ajudar a delinear os corpos de minério, ou, ainda, no caso de depósitos sedimentares, para delinear as interfaces carvão/estéril (Hoffman et al., 1982; Borsaru \& Asfahania, 2007), auxiliando no estabelecimento da correlação estratigráfica.

O teor de cinzas de uma camada de carvão, o qual representa a percentagem em massa do resíduo de sua combustão, é um exemplo de parâmetro qualitativo que pode ser previsto por perfilagem geofísica. $\mathrm{O}$ teor de cinzas está relacionado à composição mineralógica do carvão e a técnica de perfilagem mais utilizada na sua determinação tem sido a gama-gama (trata-se do perfil conhecido como density log), desenvolvida, industrialmente, na década de 70 (Borsaru et al., 1985). O perfil density é usado, geralmente, para delinear as camadas de carvão e medir sua massa específica. O teor de cinzas do carvão é estimado a partir da correlação existente entre massa específica e conteúdo de cinzas. Para que seja alcançada uma elevada acuracidade, na determinação das cinzas, é essencial, portanto, que a correlação seja igualmente elevada.

O perfil de resistividade também é capaz de caracterizar os carvões em termos de teor de cinzas, em certos casos. Segundo Bond et al. (1971) e Kayal e Das (1981), a resistividade do carvão varia com o grau de carbonização (rank), aumentando com a redução do teor de cinzas presente nas camadas de carvão de um mesmo rank. Ainda, a contagem da radiação gama natural aumenta com o aumento de folhelhos (cinzas) intercalados no carvão, mas, diferentemente da resistividade, a contagem gama independe da saturação de água

Nos depósitos de carvão brasileiros, especificamente no Rio Grande do Sul, verificou-se que existe boa correlação entre massa específica, cinza e poder calorífico, o que é verificado com a sonda density (Webber et al., 2006 e Webber et al., 2008). Esses estudos relatam, também, a existência de correlação entre a radiação gama natural emitida pelas camadas de carvão e o teor de cinzas. A correlação entre gama natural e cinzas torna possível prever o teor de cinzas por meio de perfilagem geofísica sem uso de fonte radioativa, com as vantagens já citadas. Além disso, pode-se, eventualmente, reduzir o número de sondagens com recuperação de testemunho, reduzindo custos e agilizando os processos de modelagem geológica e de teores.

Diversos perfis geofísicos registram contrastes entre carvão e os materiais estéreis adjacentes, notadamente os perfis de gama natural, resistividade, sônico, density e o neutron log (Hoffman et al., 1982). Aspectos negativos quanto ao uso do density e neutron log relacionam-se à necessidade de emprego de fontes radioativas nessas sondas (Césio-137 para o density e Amerício-Berílio para o neutron log), o que traz consigo preocupações ambientais (sempre existe a possibilidade de aprisionamento definitivo das sondas e suas fontes em furos de sondagem) e operacionais (o manuseio da fonte radioativa requer pessoal credenciado).

\section{Parâmetros de qualidade de carvão}

As características do carvão variam amplamente e desempenham papel fundamental na seleção de equipamentos, nas suas condições operacionais, desempenho e custos, tanto na lavra e no beneficiamento, quanto na usina. Carvões com maior quantidade de voláteis estão mais propensos a uma combustão prematura no sistema de moagem. Há influência dos voláteis (como primeiro indicador de reatividade) no que tange aos riscos de incêndios e explosões (Wall et al., 2001; Pohl, 1992). A pirita tem grande efeito sobre qualquer equipamento de moagem e afeta o desempenho de equipamentos de escavações (Wall et al., 2001; Costa et al., 2001), tanto é que, nos setores com alto conteúdo de enxofre, é observada, frequentemente, uma elevação dos custos operacionais das cortadeiras. Ainda, a pirita está relacionada a problemas ambientais, tais como emissão de $\mathrm{SO}_{2}$ e drenagem ácida, entre outros. Durante a drenagem das minas, feita por meio de bombas, as águas sulfurosas são lançadas no ambiente externo, provocando a elevação das concentrações de sulfatos e de ferro e a redução de pH no local de drenagem (Costa et al., 2000).

Quanto a cinzas, sabe-se que a massa específica do carvão está relacionada com o seu teor, pois, quanto maior o teor de cinzas no carvão, maior a sua massa específica e, conseqüentemente, menor a sua qualidade, reduzindo o seu poder calorífico. Isto define suas aplicações e seu valor comercial. As usinas termoelétricas se caracterizam por baixa maleabilidade quanto às especificações de qualidade do minério que alimenta o processo. Assim, o controle de parâmetros, como, por exemplo, o teor de cinzas, é essencial para o desempenho adequado da usina. Geralmente, exigências contratuais definem essas especificações de qualidade, sendo determinadas penalidades quando determinada quantidade de minério entregue não 
possui as características especificadas. Por esse motivo, impõe-se a necessidade de conhecimento da variabilidade in situ de parâmetros-chave para, então, serem utilizadas técnicas que permitam controlar a variabilidade do parâmetro no produto final (Costa et al., 2005).

\section{Materiais e métodos}

O trabalho de campo consistiu na perfilagem de 17 furos de sondagem verticais com profundidade média de 50 metros. Os furos interceptam as principais camadas de carvão de um depósito específico (Figura 1), sendo que este é formado por sete camadas denominadas CA, S1, S2, S3, M, I1 e I2. A maior parte das amostras foi obtida nas camadas $\mathrm{S} 1, \mathrm{~S} 2, \mathrm{~S} 3$ e M, tendo sido, por isso, ignoradas as demais para fins desse estudo.

A classificação das camadas foi feita com base na correlação estratigráfica por meio da descrição dos testemunhos de sondagem. O reconhecimento dos litotipos está baseado na análise visual da textura, da estrutura e da composição dos referidos litotipos. No caso de carvões, há uma descrição pormenorizada das características qualitativas, tais como o conteúdo de vitrinita, seguindo o padrão da Standards Association of Australia (Anon, 1993). Quando há intercalações dentro da camada de carvão, descrevem-se quais os tipos de impurezas estão presentes.

Os furos estão dispostos em uma malha irregular, com espaçamento entre 200 e 600 metros, com média de 300 metros. Apenas um dos furos não foi perfilado ao longo de todo seu comprimento. A seguir, foi construído um banco de dados (Tabela 1), constituído pelos resultados da perfilagem geofísica e das análises de laboratório: percentagens de cinzas, enxofre e voláteis, ou seja, parâmetros os quais poderiam mostrar correlação com gama natural ou resistividade.

Nos registros de perfilagem, foram desprezados os $25 \mathrm{~cm}$ iniciais e finais de cada camada. Foi adotado esse procedimento em função do volume de investigação das sondas e interferências sobre as leituras geofísicas dos litotipos estéreis adjacentes às camadas de carvão que estavam sendo investigadas. O reconhecimento das assinaturas geofísicas das camadas foi feito com base nas descrições e correlações com os testemunhos de sondagem.

Ainda, para determinação dos parâmetros geoquímicos, foram utilizadas as seguintes normas técnicas (da ABNT): NBR 8289 (determinação de cinzas), NBR 8295 (determinação de enxofre total) e NBR 8290 (determinação de materiais voláteis).

\section{Resultados e discussão}

\section{Assinaturas geofísicas das camadas de carvão}

Para analisar a relação entre os parâmetros químicos do carvão e aqueles resultantes da perfilagem geofísica, visando a posterior modelamento das variáveis de qualidade, ao longo do depósito de carvão, é necessário analisar, estatisticamente, as diferenças entre as distintas camadas do depósito. Na Tabela 2, pode ser observado que o parâmetro enxofre mostrou elevado coeficiente de variação, independentemente da camada analisada. Por outro lado, os valores médios de resistividade aparentam estar correlacionados aos teores médios de enxofre das camadas. Por exemplo, a camada S2, com o teor de enxofre mais elevado (2,5\%), apresentou resistividade média maior que as camadas M, S1 e S3 (Tabela 3). Entretanto, a alta variabilidade dos dados, mesmo se analisados os valores por faixa de gama natural, não permite uma previsão segura desse parâmetro, ocorrendo o mesmo em relação aos voláteis. Ainda com base nas Tabelas 2 e 3, percebe-se que a camada S2 apresenta valor médio de gama natural mais baixo que as demais e resistividade mais elevada, enquanto a camada $\mathrm{M}$ concentra-se em faixas de gama natural mais elevado e resistividade mais baixa. A camada $\mathrm{S} 3$, por sua vez, apresenta uma larga faixa de valores de gama natural, os quais variam de 30 API a 110 API. A variabilidade ou espalhamento das leituras geofísicas, dentro de uma mesma camada, está intimamente ligado à própria variabilidade que essa camada possui em seus teores. Camadas com alta variabilidade de propriedades geológicas (estruturais e/ou composicionais) possuem alta variabilidade de sinal geofísico, o que é esperado, e demonstra a sensibilidade do sensor geofísico à mudança das características fisico-químicas do minério.

Os resultados observados, nas Tabelas 2 e 3, mostram que as camadas com valor médio de resistividade mais elevada corresponderam aos valores médios de cinza mais baixos, tal que a

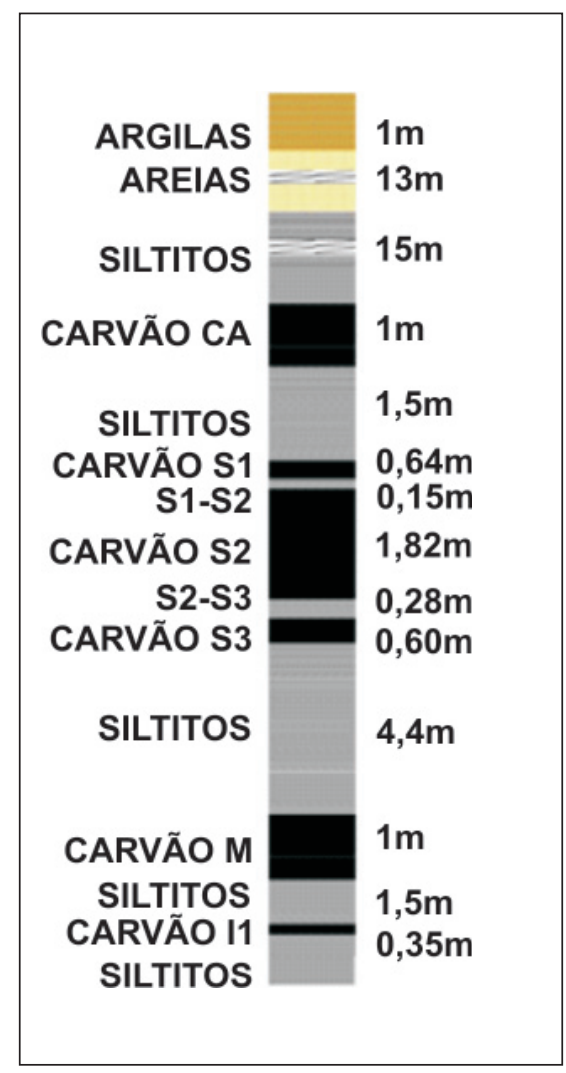

Figura 1- Coluna litológica típica do depósito de carvão estudado. 
camada $\mathrm{M}$ apresentou teor médio de cinza de $52 \%$ e resistividade de 69 Ohm.m, enquanto a camada S2 apresentou 38\% de cinzas e cerca de 106 Ohm.m. Isto está de acordo com Bond et al.(1971), pois no seu trabalho os resultados mostraram, também, que há uma variação de resistividade coma as mudanças no teor de cinzas e, ainda, a resistividade do carvão aumentava quando o seu teor de cinza diminuia.

Após análise estatística dos parâmetros de cada camada, torna-se fundamental o reconhecimento das assinaturas das várias camadas nos perfis geofísicos. O primeiro reconhecimento das assinaturas das camadas foi feito com a ajuda das descrições dos testemunhos de sondagem. A Figura 2 mostra as assinaturas das camadas, a partir das quais foram delimitados os trechos de interesse. Com base nesses limites, os valores médios de gama natural podem ser extraídos para previsão das cinzas. No presente caso, o reconhecimento primário das camadas de carvão está baseado em sua assinatura típica, isto é, pelas anomalias caracterizadas por gama natural baixo e resistividade elevada (Hoffman et al., 1982). Sabe-se, entretanto, que, em outros depósitos, litologias como arenitos e paraconglomerados apresentam assinaturas geofísicas de gama natural e resistividade similares às do carvão. No caso do depósito aqui analisado, isto não acontece, pois não há presença significativa de arenitos, muito menos com tais características, predominando, fundamentalmente, a intercalação de siltitos e carvão, conforme mostrado anteriormente na coluna litológica da Figura 1.

Para alguns furos (por exemplo o furo CAL-22 da Figura 2), foi difícil reconhecer os limites entre S2 e S3. A ausência da camada S1 foi evidente. A assinatura do gama natural, em conjunto com o perfil resistividade, não ajudou, neste caso, a marcar, de forma nítida, a camada S3. Essa assinatura, nos demais furos, foi, no entanto, registrada de forma clara pela superposição dos dois perfis (gama natural e resistividade). Nesse furo (CAL-22), as amostras de
S2 e S3 não foram aproveitadas para construção de modelos de correlação, pois apresentavam recuperação abaixo de $95 \%$ (57\% para a camada S2 e $26 \%$ para a S3).

A baixa recuperação dos testemunhos, nessas camadas, já é um indicativo do motivo pelo qual foi impossível reconhecer, claramente, onde terminava a camada S2 e onde começava a S3. A camada M, por outro lado, foi, nitidamente, marcada por ambos os perfis, sendo que esse trecho apresentou 100\% de recuperação na sondagem. Na Figura 2, a simbologia utilizada, para descrever a qualidade do carvão (BR, BB, BD, DB, DM, DD), segue o padrão da Standards Association of Australia (Anon, 1993).

Na construção do modelo proposto para previsão das cinzas, foram utilizadas 39 amostras disponíveis com recuperação acima de $92 \%$, ou seja, foram desprezadas as amostras com menor recuperação.

Nos perfis do furo CAL 24, a assinatura da camada S3 fica clara, em função da presença de material de intercalação com grande espessura (siltitos com 1,5 m) entre S2 e S3, e a ausência da camada $\mathrm{S} 1$ ficou evidente pelos perfis de resistividade e gama natural. Ainda, a assinatura da camada S2 apresentou diversos picos de resistividade, delineando a intercalação freqüente de outros materiais estéreis que ocorrem nessa camada.

Nos perfis do furo CAL-16, aparecem, novamente, as três camadas $\mathrm{S} 1$, S2 e S3, separadas da camada M por material estéril. O perfil gama natural, em conjunto com o perfil de resistividade, assinala os limites de cada camada.

\section{Estimativa dos parâmetros de qualidade}

Com base no banco de dados mostrado na Tabela 1 , foi possível constatar que existe, nesse depósito, uma correlação linear alta $(\mathrm{R}=0,94)$ entre o gama natural e o teor de cinzas. A Figura 3 (a) mostra essa correlação e a equação linear de ajuste correspondente. O erro relativo é de $\pm 10 \%$, para o intervalo de confiança de $85 \%$, com a previsão de cinzas dada pela equação linear $Y=0,36 \mathrm{X}+17,61$, sendo $Y$ o teor de cinzas (\%) e $X$ a média do gama natural (API) no trecho do perfil correspondente à camada de carvão de interesse. Dentro do intervalo de valores 20 a 120 API de gama natural (GN), considerando todos os dados (39 ao todo), os erros absoluto e médio apresentam média igual a zero, ou seja, não há uma tendência em superestimar ou subestimar as cinzas (para determinação do erro relativo é sugerida a leitura de Montgomery \& Runger, 2003).

$\mathrm{Na}$ Tabela 1, são mostrados os valores de teor de cinza previstos pelo modelo baseado no gama natural e diferenças encontradas (resíduos) com relação aos valores determinados em laboratório. O erro máximo absoluto encontrado foi de $8,5 \%$ e o mínimo de $0,1 \%$, sendo que nenhuma das amostras mostrou uma diferença entre o valor previsto e o analisado em laboratório acima de $15 \%$.

A Figura 3(b) mostra os resultados para gama natural e voláteis, onde pode ser observada, para a maioria dos dados, uma forte tendência de correlação linear entre as duas variáveis. Entretanto, aproximadamente, $20 \%$ das amostras (8 em 39) comprometem uma boa correlação. Esse nível de correlação não permite, ainda, construir um modelo para prever voláteis a partir de perfilagem. Tal ponto de vista é suportado pela análise pormenorizada dos dados (Tabela 1), a qual revela não existir uma correlação linear simples entre as variáveis teor de cinzas, voláteis e, também, com o enxofre.

O coeficiente de correlação Pearson (Isaaks \& Srivastava, 1989) para esses dados (voláteis versus gama natural) foi de -0.54 , enquanto o coeficiente de correlação ordenada de Spearman foi de -0.68 , significando que alguns poucos pares erráticos (visíveis no gráfico da Figura 3(b)) estão afetando a boa cor- 
Vládia de Souza et al.

Tabela 1 - Banco de dados de depósito de carvão, mostrando valores de cinza de laboratório (Cinza, \%), valores previstos pelo modelo baseado em gama natural (Gama Nat., API) e resíduos (Erro Absoluto, \%).

\begin{tabular}{|c|c|c|c|c|c|c|c|c|c|c|}
\hline \multirow[b]{2}{*}{ Furo } & \multirow[b]{2}{*}{ Camada } & \multirow[b]{2}{*}{$\begin{array}{c}\text { Espessura } \\
\text { (m) }\end{array}$} & \multicolumn{2}{|c|}{ Perfilagem Geofísica } & \multicolumn{3}{|c|}{ Laboratório } & \multicolumn{3}{|c|}{ Prevista pelo modelo } \\
\hline & & & $\begin{array}{l}\text { Resist. } \\
\text { (Ohm.m) }\end{array}$ & $\begin{array}{c}\text { Gama Nat. } \\
\text { (API) }\end{array}$ & $\begin{array}{c}\text { Cinza } \\
(\%)\end{array}$ & $\begin{array}{c}\mathrm{S} \\
(\%)\end{array}$ & $\begin{array}{c}\text { Voláteis } \\
\text { (\%) }\end{array}$ & $\begin{array}{c}\text { Cinza } \\
(\%)\end{array}$ & \begin{tabular}{|c|} 
Erro \\
Abs.(\%)
\end{tabular} & $\begin{array}{l}\text { Erro } \\
\text { Rel. }\end{array}$ \\
\hline CAL 1 & S2 & 1,9 & 84,1 & 48,0 & 31,6 & 3,9 & 27,0 & 35,1 & 3,5 & $11 \%$ \\
\hline CAL 1 & S3 & 0,8 & 81,0 & 66,0 & 42,4 & 2,1 & 23,8 & 41,7 & $-0,7$ & $-2 \%$ \\
\hline CAL 3 & S3 & 0,7 & 41,0 & 92,0 & 52,1 & 2,0 & 20,4 & 51,1 & $-1,0$ & $-2 \%$ \\
\hline CAL 6 & S3 & 0,6 & 93,5 & 90,0 & 47,9 & 2,0 & 21,2 & 50,4 & 2,5 & $5 \%$ \\
\hline CAL 8 & $\mathbf{M}$ & 0,7 & 93,5 & 114,0 & 54,3 & 0,4 & 21,1 & 59,1 & 4,8 & $9 \%$ \\
\hline CAL 9 & S1 & 0,7 & 49,3 & 57,0 & 41,3 & 2,4 & 28,8 & 38,4 & $-2,9$ & $-7 \%$ \\
\hline CAL 9 & S2 & 0,5 & 112,2 & 60,0 & 40,1 & 2,3 & 27,5 & 39,5 & $-0,6$ & $-2 \%$ \\
\hline CAL 9 & S3 & 1,1 & 50,1 & 75,0 & 46,0 & 1,8 & 24,2 & 44,9 & $-1,1$ & $-2 \%$ \\
\hline CAL 10 & $M$ & 1,0 & 65,1 & 85,5 & 45,1 & 2,2 & 32,7 & 48,8 & 3,7 & $8 \%$ \\
\hline CAL 10 & S1 & 1,0 & 48,0 & 79,0 & 42,8 & 5,4 & 32,3 & 46,4 & 3,6 & $8 \%$ \\
\hline CAL 10 & S2 & 2,4 & 49,1 & 54,0 & 37,6 & 0,9 & 29,2 & 37,3 & $-0,3$ & $-1 \%$ \\
\hline CAL 10 & S3 & 0,8 & 41,3 & 51,5 & 35,5 & 2,9 & 28,3 & 36,4 & 0,9 & $2 \%$ \\
\hline CAL 12 & $M$ & 0,9 & 87,2 & 85,0 & 48,9 & 2,4 & 35,4 & 48,6 & $-0,3$ & $-1 \%$ \\
\hline CAL 12 & S1 & 0,6 & 68,7 & 111,0 & 56,1 & 1,1 & 22,6 & 58,0 & 1,9 & $3 \%$ \\
\hline CAL 12 & S2 & 2,4 & 68,7 & 76,5 & 42,1 & 0,8 & 21,3 & 45,5 & 3,4 & $8 \%$ \\
\hline CAL 12 & S3 & 0,6 & 63,6 & 56,5 & 39,1 & 4,0 & 36,1 & 38,2 & $-0,9$ & $-2 \%$ \\
\hline CAL 13 & $M$ & 1,4 & 70,0 & 99,0 & 53,0 & 1,4 & 20,3 & 53,7 & 0,7 & $1 \%$ \\
\hline CAL 13 & S1 & 0,8 & 125,5 & 49,0 & 34,1 & 1,0 & 26,4 & 35,5 & 1,4 & $4 \%$ \\
\hline CAL 13 & S2 & 3,4 & 90,9 & 84,0 & 46,1 & 1,1 & 22,2 & 48,2 & 2,1 & $5 \%$ \\
\hline CAL 14 & $M$ & 1,2 & 74,7 & 85,5 & 51,4 & 2,9 & 21,4 & 48,8 & $-2,6$ & $-5 \%$ \\
\hline CAL 14 & S1 & 0,5 & 150,8 & 61,0 & 36,9 & 0,7 & 25,5 & 39,8 & 2,9 & $8 \%$ \\
\hline CAL 14 & S2 & 2,5 & 166,6 & 55,0 & 33,9 & 2,1 & 28,3 & 37,6 & 3,7 & $11 \%$ \\
\hline CAL 15 & $M$ & 1,1 & 68,1 & 102,0 & 55,0 & 1,3 & 19,2 & 54,8 & $-0,2$ & $0 \%$ \\
\hline CAL 15 & S2 & 1,8 & 116,0 & 39,0 & 28,4 & 2,7 & 28,4 & 31,8 & 3,4 & $12 \%$ \\
\hline CAL 16 & $M$ & 1,0 & 64,0 & 79,5 & 46,5 & 1,7 & 22,4 & 46,6 & 0,1 & $0 \%$ \\
\hline CAL 16 & S2 & 2,5 & 107,1 & 59,0 & 42,6 & 1,5 & 25,9 & 39,1 & $-3,5$ & $-8 \%$ \\
\hline CAL 16 & S3 & 0,5 & 65,7 & 71,5 & 43,5 & 1,0 & 23,6 & 43,7 & 0,2 & $0 \%$ \\
\hline CAL 19 & $M$ & 1,4 & 71,7 & 88,5 & 51,9 & 0,6 & 20,3 & 49,8 & $-2,1$ & $-4 \%$ \\
\hline CAL 21 & $M$ & 0,8 & 72,1 & 98,0 & 52,4 & 1,1 & 21,7 & 53,3 & 0,9 & $2 \%$ \\
\hline CAL 21 & S3 & 0,9 & 59,2 & 108,0 & 60,9 & 0,4 & 17,7 & 57,0 & $-3,9$ & $-6 \%$ \\
\hline CAL 22 & $M$ & 1,5 & 60,3 & 95,0 & 52,3 & 1,2 & 21,7 & 52,2 & $-0,1$ & $0 \%$ \\
\hline CAL 23 & $M$ & 1,0 & 87,5 & 79,0 & 47,6 & 1,8 & 31,5 & 46,4 & $-1,2$ & $-3 \%$ \\
\hline CAL 24 & $M$ & 1,1 & 77,4 & 89,0 & 50,3 & 2,2 & 23,1 & 50,0 & $-0,3$ & $-1 \%$ \\
\hline CAL 24 & S2 & 2,6 & 111,3 & 54,5 & 39,6 & 1,9 & 29,3 & 37,5 & $-2,1$ & $-5 \%$ \\
\hline CAL 24 & S3 & 1,0 & 77,2 & 95,0 & 53,2 & 0,6 & 20,5 & 52,2 & $-1,0$ & $-2 \%$ \\
\hline CAL 21 & S2 & 2,1 & 114,9 & 53,5 & 35,8 & 5,3 & 24,9 & 37,1 & 1,3 & $4 \%$ \\
\hline CAL 16 & S1 & 0,6 & 46,2 & 46,5 & 39,2 & 4,2 & 26,4 & 34,6 & $-4,6$ & $-12 \%$ \\
\hline CAL 14 & S3 & 0,9 & 123,4 & 30,0 & 32,3 & 0,9 & 23,1 & 28,5 & $-3,8$ & $-12 \%$ \\
\hline CAL 1 & M & 1,4 & 42,5 & 104,5 & 64,2 & 1,4 & 18,8 & 55,7 & $-8,5$ & $-13 \%$ \\
\hline \multicolumn{9}{|c|}{ Erro mínimo absoluto: } & 0,1 & $0 \%$ \\
\hline \multicolumn{9}{|c|}{ Erro máximo absolute: } & 8,5 & $13 \%$ \\
\hline \multicolumn{10}{|c|}{ Fração de dados com erro relativo maior que $10 \%$ : } & $16 \%$ \\
\hline
\end{tabular}


Estimativa de qualidade de carvão por meio de perfilagem geofísica de gama natural e resistividade

Tabela 2 - Resumo estatístico dos parâmetros a serem estimados, baseando-se nas amostras analisadas a partir dos testemunhos de sondagem.

\begin{tabular}{c|c|c|c|c|c|c|c|c|c}
\hline & \multicolumn{3}{|c|}{ S (enxofre, \%) } & \multicolumn{3}{c}{ Cinzas (\%) } & \multicolumn{3}{c}{ Voláteis (\%) } \\
\hline Camada & Mín-Máx & Média & CV* $^{*}$ & Mín-Máx & Média & CV $^{*}$ & Mín-Máx & Média & CV $^{*}$ \\
\hline M & $0,4-2,9$ & 1,4 & 43 & $45-64$ & 52 & 9 & $19-35$ & 24 & 23 \\
\hline S1 & $0,7-4,2$ & 2,0 & 65 & $34-56$ & 42 & 17 & $23-32$ & 27 & 11 \\
\hline S2 & $1,1-5,3$ & 2,5 & 48 & $28-46$ & 38 & 14 & $21-29$ & 26 & 10 \\
\hline S3 & $0,4-5,4$ & 2,0 & 75 & $32-61$ & 45 & 18 & $18-36$ & 24 & 20 \\
\hline
\end{tabular}

${ }^{*}$ Coeficiente de variação em \% (CV=Desvio-Padrão/Média).

Tabela 3 - Resumo estatístico dos parâmetros determinados por meio de perfilagem geofísica: resistividade e gama natural.

\begin{tabular}{c|c|c|c|c|c|c|c}
\hline & \multicolumn{3}{|c|}{ Resistividade (Ohm-m) } & \multicolumn{3}{c|}{ Gama Natural (API) } & \multirow{2}{*}{$\begin{array}{c}\text { Número } \\
\text { de Amostras }\end{array}$} \\
\cline { 1 - 6 } Camada & Mín-Máx & Média & CV & Mín-Máx & Média & CV DP* & 13 \\
\hline M & $42-94$ & 69 & 19 & $16-23$ & 95 & 11 & 6 \\
\hline S1 & $41-151$ & 80 & 53 & $9-22$ & 70 & 33 & 6 \\
\hline S2 & $651-167$ & 106 & 24 & $8-17$ & 60 & 21 & 10 \\
\hline S3 & $410-123$ & 70 & 33 & $6-22$ & 75 & 31 & 10 \\
\hline
\end{tabular}

${ }^{*}$ Coeficiente de variação em \% (CV=Desvio-Padrão/Média).
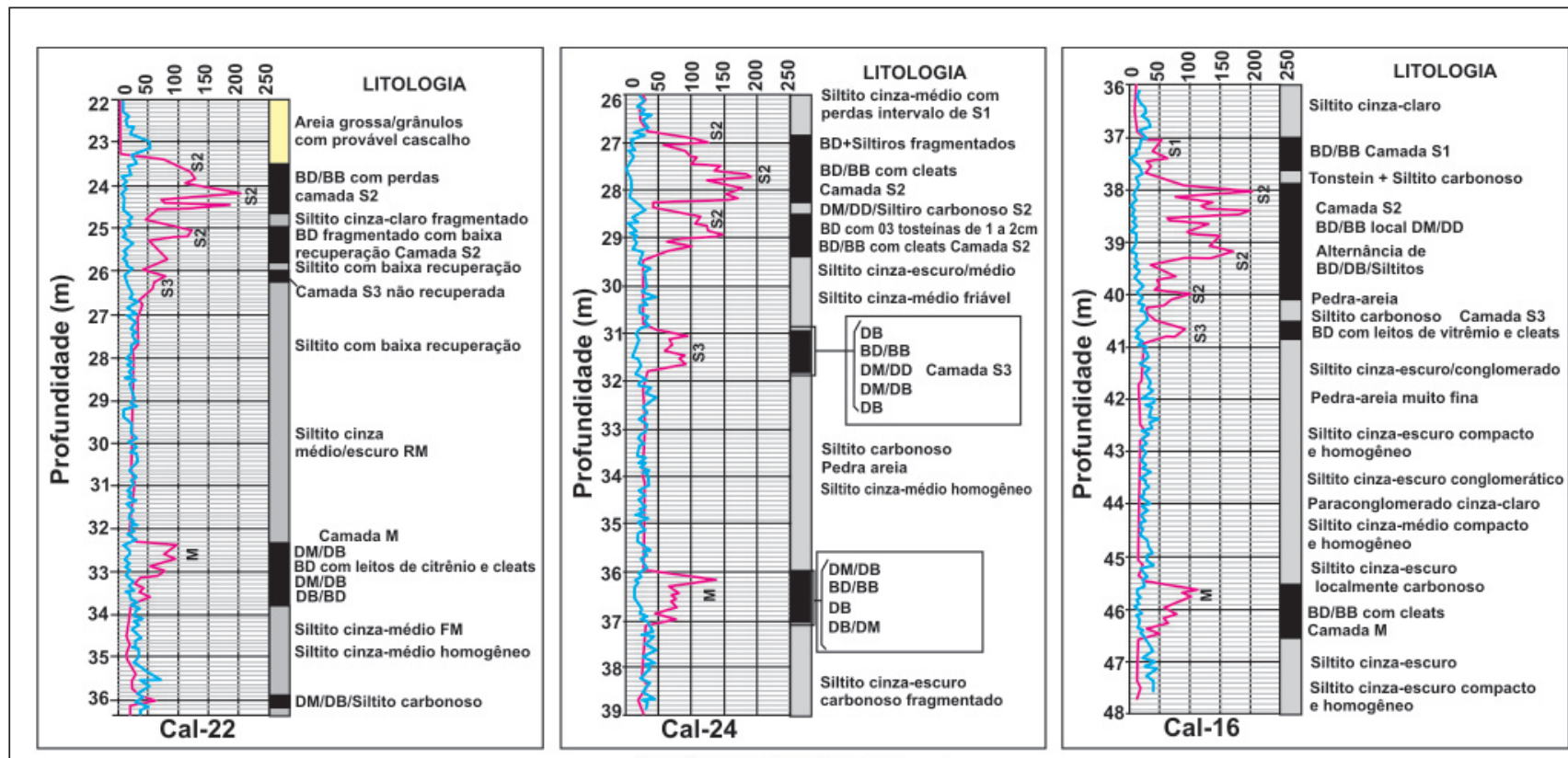

GN (API) RES (Ohm.m)

Nota: os valores de gama natural estão divididos por um fator de escala (uma constante) igual a 5.

Figura 2 - Perfil de resistividade (linha vermelha) e gama natural (linha azul) ao lado da descrição litológica dos furos CAL-22, CAL-24 e CAL16 , respectivamente. Nota: os valores de gama natural estão divididos por um fator de escala (uma constante) igual a 5 .

658 REM: R. Esc. Minas, Ouro Preto, 63(4): 653-660, out. dez. 2010 
Vládia de Souza et al.

relação que existe entre voláteis e gama natural. As mesmas oito amostras erráticas não revelam, por outro lado, nenhuma anomalia de gama natural ou resistividade, mas quase todas (5 em 8 ) apresentam voláteis acima de $30 \%$, conforme pode ser observado na Figura 3 (b). Ainda, o parâmetro resistividade e gama natural não revelaram correlação com quaisquer outras variáveis qualitativas.

\section{Conclusões}

Com a realização desse estudo de caso, foi verificada a existência de uma boa correlação entre teor de cinzas de camadas de carvão e os registros de gama natural. Para esse depósito, portanto, é possível prever o teor de cinzas com o uso apenas de perfilagem de gama natural, considerando um pequeno erro relativo de $\pm 10 \%$. Além de servirem como uma antecipação dos resultados de análises químicas do carvão, contido nos testemunhos de sondagem, as estimativas de cinzas, derivadas dos valores de gama natural, podem ser usadas como informação secundária (de baixo custo) para avaliar a qualidade do carvão durante a etapa de estimativa de recursos do depósito. Ainda, o fato de o modelo estar baseado apenas no gama natural, dispensando o uso de sondas radioativas, torna o método muito atrativo, pois dispensa preocupações com a possibilidade de aprisionamento definitivo de sondas e suas fontes nos furos de sondagem, bem como dispensa preocupação com ações operacionais. Estas estão relacionadas ao manuseio da fonte radioativa, manuseio este que requer pessoal credenciado.

\section{Agradecimentos}

Nossos agradecimentos especiais à Copelmi Mineração por todo apoio logístico, ao Conselho Nacional de Desenvolvimento Científico e Tecnológico-CNPq e à Coordenação de Aperfeiçoamento de Pessoal de Nível Superior-CAPES, que vêm financiando os projetos de perfilagem geofísica do Laboratório de Pesquisa Mineral/LPM-UFRGS, por meio de concessão de bolsas de pesquisa.

\section{Referências bibliográficas}

ABNT-ASSOCIAÇÃO BRASILEIRA DE NORMAS TÉCNICAS. NBR 8289:1983 (versão Corrigida: 1987) -Carvão mineral Determinação do teor de cinzas. 1983. 4p. (Essa norma prescreve o método para determinar o teor de cinzas em carvão mineral).

ABNT-ASSOCIAÇÃO BRASILEIRA DE NORMAS TÉCNICAS. NBR 8295:1983 - Carvão mineral - Determinação do enxofre total pelo processo de combustão (hidróxido de sódio). 1983. 7p. (Essa norma prescreve o método para determinar o teor de enxofre total em carvão mineral).

ABNT-ASSOCIAÇÃO BRASILEIRA DE NORMAS TÉCNICAS. NBR 8290:1983 - Carvão mineral - Determinação do teor de materiais voláteis. 1983. 3p. (Essa norma prescreve o método para determinar o teor de matériais voláteis de carvão mineral).

ANON, AUSTRALIAN STANDARD (STANDARDS ASSOCIATION OF AUSTRALIA). AS2519: Guide to the technical evaluation of higher rank coal deposits. Australian Standard. Committee MN/1 coal and coke, 1993. 119p.

BOND, L.O., ALGER, R.P., SCHMIDT, A.W. Well log interpretation in coal mining and rock mechanics. Soil Mech. Eng., Trans., v. 250, p.355-362, 1971.

BORSARU, M., CHARBUCINSKI, J., EISLER, P. L., YOUL, S. F. Determination of ash content in coal by borehole logging in dry

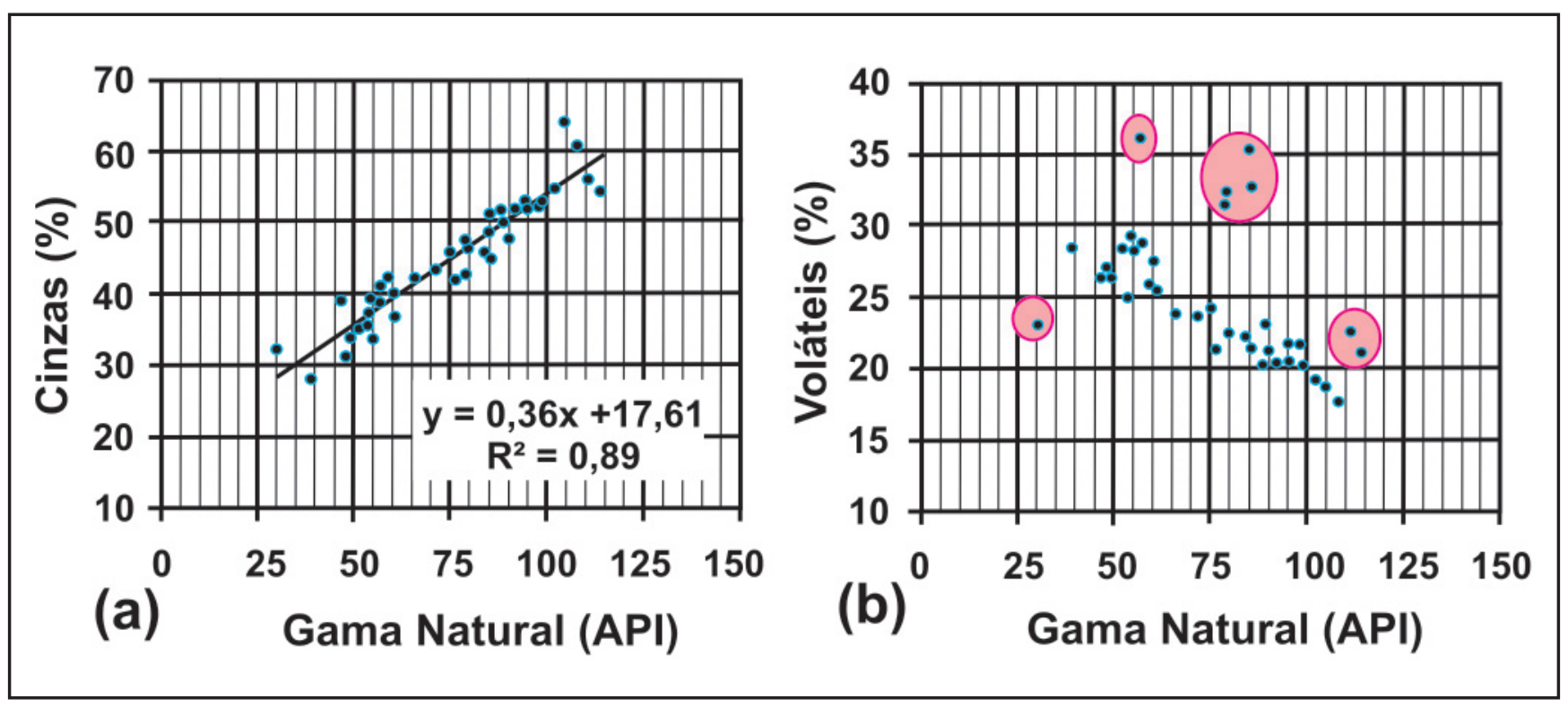

Figura 3 - (a) Modelo linear proposto para previsão do teor de cinzas (\%) a partir do gama natural. (b) Gráfico de dispersão entre voláteis (\%) e gama natural. Pontos circulados correspondem às amostras erráticas, apresentando, em sua maioria, voláteis acima de $30 \%$. 
boreholes using gamma-gamma methods. Geoexploration, v. 23, n.4, p.503-518, 1985.

BORSARU, M., ASFAHANIA, J. Lowactivity spectrometric gamma-ray logging technique for delineation of coal/rock interfaces in dry blast holes. Applied Radiation and Isotopes, v. 65, n.6, p.748755, 2007.

COSTA, J. F. C. L., KOPPE, J., CORREA, K. Redução da geração de drenagem ácida de mina em depósitos de rejeitos de mineração de carvão. REM - Revista da Escola de Minas, Ouro Preto, v. 53, n. 3, p. 187-192, 2000.

COSTA, J. F. C. L. , SOUZA, L. E., KOPPE, J. , PILGER, G. Predicting the spatial distribution of pyrite concretions and its influence in continuous coal mining. Mineral Resources Engineering, London, v. 10 , n. 4, p. $415-425,2001$

COSTA, J. F. C. L., KOPPE, J. C., GAMBIN, F. Estratégia de controle de qualidade de minério na lavra usando simulação geoestatística. REM - Revista da Escola de Minas, Ouro Preto, v. 58, n. 3, p. 193 200, 2005.
HOFFMAN, G.L., JORDAN, G. R., WALLIS, G.R. Geophysical borehole logging handbook for coal exploration. The Coal Mining Research Centre, Edmonton, Alberta, Canada, 1982. 270p.

ISAAKS, H. E., SRIVASTAVA, M.R. An introduction to applied geostatistics. New York, USA: Oxford University Press, Inc., 1989. 560p.

KAYAL, J.R., DAS, L.K. A method of estimating ash content of coal from combined resistivity and gamma-ray logs. Geoexploration, v. 19, n.3, p.193-200, 1981.

MONTGOMERY, D. C., RUNGER, G. C. Applied statistics and probability for engineers. (3. ed.). New York, USA: John Wiley \& Sons, Inc., 2003. Chapter 11, p.372-410.

POHL, J. H. Intensive course on combustion technology. Australian Combustion Technology Centre, ACIRL Limited, 1992.

WALL, T., ELLIOTT, L., SANDERS, D., CONROY, A. A review of the state-of-the-art in coal blending for power generation final report - project 3.16 (Technology assessment report 14). Cooperative research centre for black coal utilization Established and supported under the Australian Government's Cooperative Research Centers Program. Advanced Technology Centre, The University of Newcastle. 2001. 93p.

WEBBER, T., SAlVADORETTI, P., OLIVEIRA, L. J., COSTA, J. F. C. L., KOPPE, J. C., CARVALHO FILHO, J. A. de, BASTIANI, G. A. Estimativa de parâmetros indicadores de qualidade de carvão a partir de perfilagem geofísica - Mina do Cerro - Cachoeira do Sul/RS. In: CONGRESSO BRASILEIRO DE MINA A CÉU ABERTO E CONGRESSO BRASILEIRO DE MINA SUBTERRÂNEA, 4. Anais... Belo Horizonte: IBRAM, 2006. p. 1-13. (CDROM)

WEBBER, T., SALVADORETTI, P., COSTA, J. F. C. L., KOPPE, J. Estimativa de qualidade de carvão usando krigagem das indicatrizes aplicadas a dados obtidos por perfilagem geofísica. In: CONGRESSO BRASILEIRO DE MINA A CÉU ABERTO E CONGRESSO BRASILEIRO DE MINA SUBTERRÂNEA, 5. Belo Horizonte: IBRAM, 2008. v. 1. p. 1-16.

Artigo recebido em 21/08/2009 e aprovado em 19/03/2010.

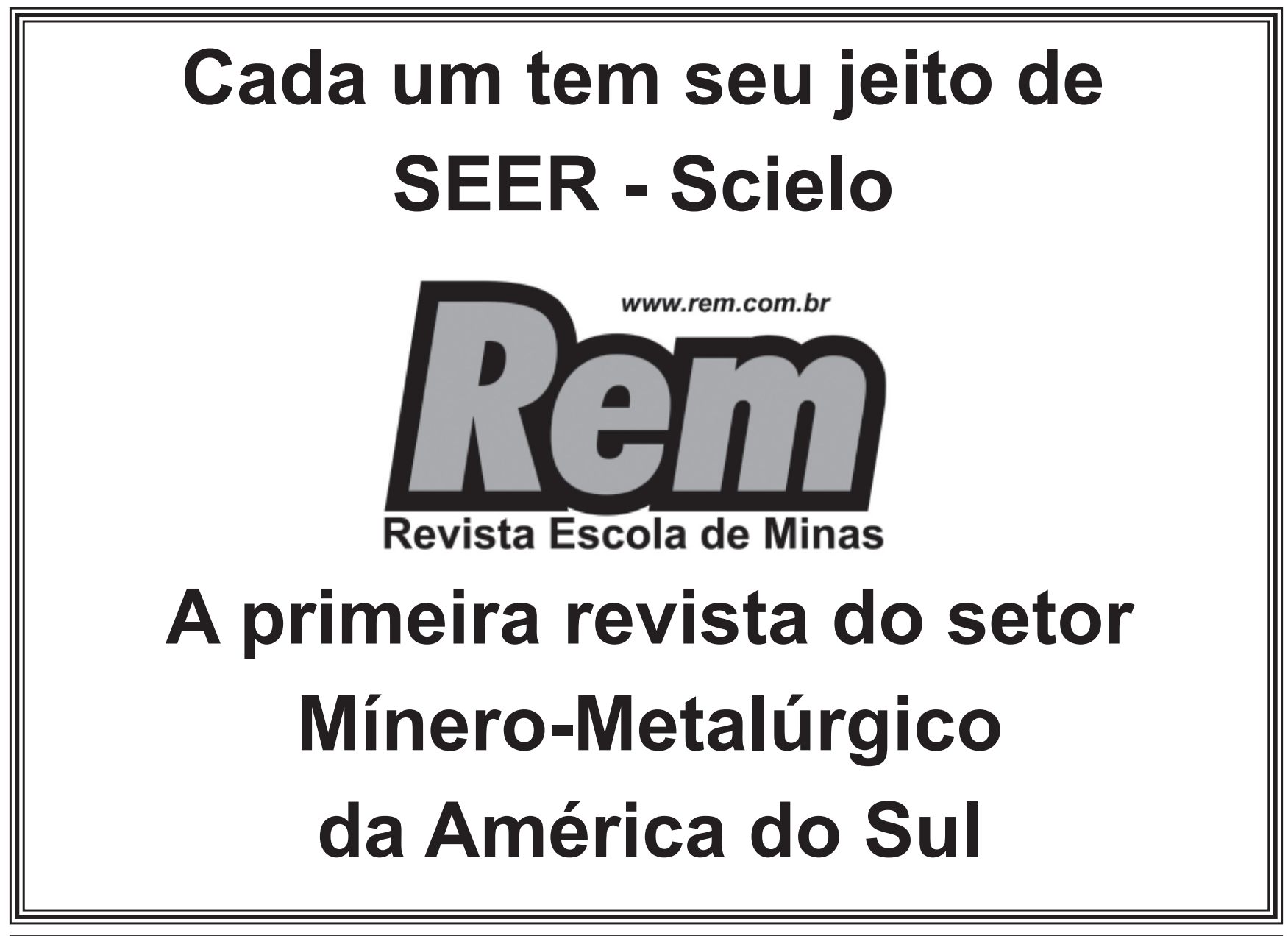

